\title{
The Effects of Demecolcine, Alone or in Combination with Sucrose on Bovine Oocyte Protrusion Rate, MAPK1 Protein Level and C-Mos Gene Expression Level
}

\author{
Yan Gao Jiusheng Ren ${ }^{a}$ Liqun Zhang ${ }^{b}$ Yonghong Zhang ${ }^{a}$ Xinhui Wu \\ Hao Jiang ${ }^{\mathrm{a}}$ Fangfang $\mathrm{Xu}^{\mathrm{a}}$ Bao Yuan ${ }^{\mathrm{a}}$ Xianfeng Yu $\mathrm{u}^{\mathrm{a}}$ Jiabao Zhang ${ }^{\mathrm{a}, \mathrm{c}}$ \\ aLaboratory Animal Center, College of Animal Sciences, Jilin University, ${ }^{\circ}$ The 1st Hospital, Jilin University, \\ cjilin Provincial Key Laboratory of Animal Embryo Engineering, College of Veterinary Medicine, Jilin \\ University, Changchun, China
}

\section{Key Words}

Demecolcine $\cdot$ Bovine oocyte $\cdot$ C-mos $\cdot$ MAPK1

\begin{abstract}
Aims: Our study aims to clarify the effects of demecolcine, alone or in combination with sucrose on bovine oocyte protrusion rate, MAPK1 protein level and c-mos gene expression level. Methods: The effects of the demecolcine concentration, treatment duration, and synergistic effects with sucrose solution on the rate of membrane protrusions of bovine oocytes were investigated. Using real-time fluorescent quantitative PCR, western blot analysis, and immunofluorescence assays, the expression of the maternal c-mos gene, the protein level of mitogen-activated protein kinase 1 (MAPK1), and the change in the localization of spindles and nuclei during the demecolcine treatment were analyzed in bovine oocytes. Results: Treatment of bovine oocytes with both demecolcine $(0.6 \mu \mathrm{g} / \mathrm{mL})$ and sucrose $(0.05$ $\mathrm{M})$ for $1 \mathrm{~h}$ led to the highest rate of membrane protrusions, and synergistic effects were also observed. Real-time fluorescent quantitative PCR analysis revealed that the demecolcine treatment up-regulated the expression of the maternal c-mos gene. Western blot analysis indicated that the demecolcine treatment enhanced the protein level of MAPK1 in bovine oocytes. Immunofluorescence analysis indicated that the spindles and nuclei were localized at the place of the membrane protrusions. Conclusions: The present results suggest that demecolcine might contribute to the activation of the Mos/MAPK pathway and affect spindle structure. These results provide a reference for more efficient generation of enucleated bovine oocytes.
\end{abstract}

Y. Gao and J. Ren contributed equally to this article. 


\section{Introduction}

Since Wilmut et al. developed the somatic nuclear transfer technology to clone "Dolly" [1], new cloned animals have been produced continuously. Although somatic nuclear transfer technology is constantly being optimized and improved, cloning efficiency remains low (approximately 3-4\%). Cloning technology involves many steps, and a critical role in determining the cloning efficiency is played by the enucleation of oocytes because the success of animal cloning is the result of the continuous embryo transfer of a large number of reconstructed embryos. In addition, the completeness of the enucleation and the amount of aspirated cytoplasm directly affect the development rate of reconstructed embryos. Thus, an improved understanding of the mechanism of enucleation is critical to improving the current enucleation methods.

The methods for the enucleation of oocytes are divided into two categories, chemically assisted enucleation and physical enucleation, based on the involvement of chemicals in the process. Chemically assisted enucleation utilizes certain chemicals to induce membrane protrusions in the oocytes, and the nuclei are removed accurately based on the membrane protrusions. The most frequently used chemicals are demecolcine, cycloheximide [2], and caffeine [3], such chemicals have been applied successfully in the production of cloned cattle [4], pigs [5] and sheep [6]. Compared to physical enucleation, chemically assisted enucleation is more accurate, more complete, involves less aspirated cytoplasm [7] and has been widely applied in the cloning of large livestock because their oocytes contain larger lipid droplets and because it is impossible to visualize the nuclei under a normal microscope [8]. Chemically assisted enucleation induces membrane protrusions in the oocytes, and the nuclei can be removed accurately based on the protrusions.

Demecolcine is able to destroy the 3-dimensional structure of spindles, thus causing chromosome condensation and leading to membrane protrusions. Past studies on the mechanism of enucleation induced by demecolcine in goats indicated that during the process of membrane protrusion, demecolcine affected the activities of maturation-promoting factor (MPF) and MAPK [9], which were directly correlated with the meiosis of the oocytes, zygote formation, and the late stage of embryonic development [10]. Therefore, we investigated the effects of demecolcine concentration, treatment duration, and co-treatment with sucrose on the membrane protrusion rate of bovine oocytes.

Demecolcine was previously shown to affect the activity and phosphorylation of MAPK $[3,9]$. However, the action of demecolcine on the upstream regulator factor c-mos has not been reported. Here, we employed real-time fluorescent quantitative PCR, western blot analysis, and immunofluorescence assays to investigate the effects of demecolcine on the expression of the maternal c-mos gene, the protein level of MAPK1 in bovine oocytes, and the change in the localization of spindles and nuclei in bovine oocytes during this process, which is conducive to the further improvement of chemically assisted enucleation methods.

\section{Materials and Methods}

The collection and in vitro maturation of bovine oocytes

Ovaries were collected in Jilin Province Changchun Haoyue Halal Meat Co., Ltd, China, stored in saline containing penicillin and streptomycin at $37^{\circ} \mathrm{C}$, and shipped to the laboratory within $3 \mathrm{~h}$ after collection. After rinsing the ovaries 3 times with saline, ovaries that had ovarian follicles 2-8 $\mathrm{mm}$ in diameter were collected using a 10-mL syringe equipped with a number 18 needle. The follicles were placed into 50-mL centrifuge tubes and incubated for $15 \mathrm{~min}$ in a $37^{\circ} \mathrm{C}$ water bath. After the precipitation of the oocytes, the supernatant was removed, the cells were resuspended in PVA-TL-HEPES (0.1\% polyvinyl alcohol (PVA)), and the suspension was transferred to a $60-\mathrm{mm}$ petri dish to let it stand for $5 \mathrm{~min}$. Under a stereomicroscope, cumulus-oocyte-complexes (COCs) that were surrounded by at least 3 layers of cumulus cells and exhibited dense and evenly distributed cytoplasm were selected. The oocytes were washed 3 times with PVA-TLHEPES, 3 times with maturation medium (fetal calf serum $(10 \%, v / v)$, pyruvate $(1 \%)$, follicle-stimulating 
hormone (0.5\%), $\beta$-estradiol (0.1\%) and double antibiotics (1\%), and transferred to medium droplets that were previously balanced in an incubator at a density of 10-15 COCs per $100 \mu \mathrm{L}$ droplet. In each $60-\mathrm{mm}$ petri dish, 12 droplets were covered with mineral oil and cultured for $24 \mathrm{~h}$ at $39{ }^{\circ} \mathrm{C}$ and $5 \% \mathrm{CO}_{2}$.

The treatment of bovine oocytes with sucrose, demecolcine, or both

The pretreatment of sucrose could promote the localization of spindles within the MII oocyte [11]. Small hyaline protuberant alabastrum was formed in the cytoplasm of the oocyte treated by sucrose [12]. Therefore, bovine oocytes were treated with sucrose.

Twenty-four hours after the in vitro maturation, the spreading of the cumulus cells surrounding the oocytes was monitored. The COCs were transferred to a solution containing $0.5 \%$ hyaluronidase, and the cumulus cells were removed by gently blowing and flushing with a micropipet. The oocytes that had already secreted the first polar body were chosen and washed 3 times with in vitro maturation medium (IVM medium). Some oocytes were transferred into droplets with either $0.05 \mathrm{M}$ or $0.07 \mathrm{M}$ sucrose and were then incubated for $0.5 \mathrm{~h}$ or $1 \mathrm{~h}$ in a $\mathrm{CO}_{2}$ incubator; some oocytes were treated with demecolcine at various concentrations $(0.4,0.5,0.6,0.7$, or $0.8 \mu \mathrm{g} / \mathrm{mL})$ for $0.5 \mathrm{~h}$ or $1 \mathrm{~h}$; and some oocytes were treated with $0.05 \mathrm{M}$ sucrose in combination with various concentrations of demecolcine for $0.5 \mathrm{~h}$ or $1 \mathrm{~h}$. After the treatment, the oocytes were stained with Hoechst 33342 dye $(10 \mu \mathrm{g} / \mathrm{mL})$ for $15 \mathrm{~min}$, membrane protrusion rate was estimated by direct counting using a microscope during enucleation. The mathematical equation is: Protrusion rate $=$ The number of oocytes with membrane protrusions $\times 100 \% /$ The number of total oocyte.

Fluorescent quantitative PCR of maternal c-mos gene

Bovine oocytes that had matured for $24 \mathrm{~h}$ and had already secreted the first polar body were chosen and divided into 3 groups: a) no treatment, b) treated with $0.05 \mathrm{M}$ sucrose only, and c) treated with both 0.05 $\mathrm{M}$ sucrose and $0.6 \mu \mathrm{g} / \mathrm{mL}$ demecolcine. Total cellular RNA was extracted using TRIzol Reagent (Invitrogen, Beijing, China) from the bovine oocytes of the aforementioned three groups and detected using $1 \%$ agarose gel electrophoresis.

Based on the mRNA sequence of the maternal gene c-mos retrieved from the NCBI GenBank (Gene ID: 444869), PCR primers were designed (Forward primer: CCAACATCCTCATCAGTGAGC, Reverse primer: GTGATGGCGAAGGAGTAGATG), and the expected amplicon size was $186 \mathrm{bp}$. The cDNA was generated using a reverse transcription kit (Takara, Dalian, China) and was stored in a $-20^{\circ} \mathrm{C}$ freezer. The cDNA was later used as a template in fluorescent quantitative PCR. The PCR reaction system included $\mathrm{ddH}_{2} \mathrm{O}(6.0 \mu \mathrm{L})$, RealMasterMix $(10 \mu \mathrm{L})$, primers $(1 \mu \mathrm{L}$ each at the concentration of $10 \mathrm{pmol} / \mu \mathrm{L})$, and cDNA $(2.0 \mu \mathrm{L})$. The PCR reaction was as follows: denaturation at $95{ }^{\circ} \mathrm{C}$ for 1 min followed by 45 cycles of $94{ }^{\circ} \mathrm{C} 20 \mathrm{sec}, 6{ }^{\circ} \mathrm{C} 20$ sec, and $72{ }^{\circ} \mathrm{C} 45 \mathrm{sec}$. Melting curve was used to prove specificity of RT-PCR amplification. The quantitative analysis of the expression of mRNA of the maternal c-mos gene was performed using the relative quantitation method (2- $2^{-\Delta C t}$ method). Each cDNA sample was assayed 3 times.

Detection of the MAPK1 protein level using western blot analysis

The bovine $\beta$-actin and MAPK1 (catalog\#: sc-154) primary antibodies were purchased from Santa Cruz. The bovine oocytes were treated with $0.6 \mu \mathrm{g} / \mathrm{mL}$ demecolcine, rinsed 3 times with D-PBS, transferred to $1.5-\mathrm{mL}$ centrifuge tubes, and added to $200 \mu \mathrm{L}$ of protein lysis solution. After vigorously shaking, the tubes were centrifuged at $12,000 \mathrm{xg}$ for $6 \mathrm{~min}$ at $4{ }^{\circ} \mathrm{C}$. The supernatant was transferred to a new centrifuge tube, and the pellet was discarded. The total protein of the control group was extracted using the same method and stored at $-80^{\circ} \mathrm{C}$. Fifty micrograms of the protein samples was mixed with $5 \mathrm{x}$ loading buffer, boiled for $10 \mathrm{~min}$ in a $105^{\circ} \mathrm{C}$ water bath, and subjected to electrophoresis with $12 \%$ SDS-PAGE. The proteins were electrotransferred to a nitrocellulose membrane with the pore size of $0.45 \mu \mathrm{m}$. After $2 \mathrm{~h}$ of blocking with nonfat milk at room temperature, the membrane was incubated with the primary antibodies against MAPK1 or $\beta$-actin at $4{ }^{\circ} \mathrm{C}$ overnight, and peroxidase-conjugated goat anti-rabbit IgG antibody (Boster, Wuhan) was then added and incubated at room temperature for $2 \mathrm{~h}$. The X-ray film was exposed using the chemiluminescence method.

We taked a photograph for film using gelatum image processing system. The grayscale value of every specific strap in the image was digitized using GIS1000 analysis software. The MAPK1 protein expression difference between the demecolcine treatment group and the control group was analysed using SPSS version 13.0. 
Immunofluorescence staining of bovine oocytes

Oocytes that had matured for $24 \mathrm{~h}$ and had already secreted the first polar body were chosen, rinsed 3 times with D-PBS, transferred into 4\% paraformaldehyde droplets, and fixed for $20 \mathrm{~min}$ at room temperature. The oocytes were aspirated using a mouth pipet and washed 3 times with D-PBS for 5 min each. Approximately $200 \mu \mathrm{l}$ of $1 \%$ Triton X-100 was added to a 24-well culture plate to perform permeabilization of the zona pellucida and the cell membrane of oocytes. After incubation in a $\mathrm{CO}_{2}$ incubator overnight, the oocytes were aspirated and washed with D-PBS 3 times for 5 min each. The oocytes were then transferred into the blocking solution droplets (1\% bovine serum albumin and $0.01 \%$ Triton X-100 in dulbecco's phosphate buffered saline (D-PBS)) and incubated in a $\mathrm{CO}_{2}$ incubator for $4 \mathrm{~h}$. The oocytes were aspirated, washed with D-PBS 3 times for 5 min each, and incubated in anti- $\alpha$-tubulin primary antibody droplets in $\mathrm{CO}_{2}$ incubator for $2 \mathrm{~h}$. The oocytes were aspirated, washed with D-PBS 3 times for 5 min each, and incubated in FITC-labeled secondary antibody droplets in a $\mathrm{CO}_{2}$ incubator for $2.5 \mathrm{~h}$. The oocytes were aspirated, washed with D-PBS 3 times for $5 \mathrm{~min}$ each, and incubated in $10 \mu \mathrm{g} / \mathrm{mL}$ propidium iodide (PI) staining solution droplets in a $\mathrm{CO}_{2}$ incubator for $20 \mathrm{~min}$. The results were observed under an inverted fluorescence microscope.

\section{Statistical analysis}

The data were expressed in the form of the mean \pm standard deviation (SD) and analyzed using oneway analysis of variance (ANOVA) using the SPSS 13.0 software package. The Least Significant Difference was used to test the significance of differences.

\section{Results}

SPSS analysis of oocyte membrane protrusion induced by sucrose at various concentrations and at different incubation times revealed that no oocyte membrane protrusion was induced regardless of treatment time $(0.5 \mathrm{~h}$ or $1 \mathrm{~h})$ or concentration $(0.05$ $\mathrm{M}$ or $0.07 \mathrm{M}$ ). Bovine oocytes stained with Hoechst 33342 demonstrated that sucrose alone induced no membrane protrusions.

Table 1. The effect of demecolcine treatment on the membrane protrusion rate of bovine oocytes. Different letters in the same column indicate that the difference between the number is statistically significant $(\mathrm{P}<0.05)$

\begin{tabular}{ccccc}
\hline $\begin{array}{c}\text { Concentration of } \\
\text { demecolcine } \\
(\mu \mathrm{g} / \mathrm{mL})\end{array}$ & $\begin{array}{c}\text { Demecolcine treatment alone for 0.5 h } \\
\text { No. of } \\
\text { oocytes }\end{array}$ & $\begin{array}{c}\text { Membrane protrusion rate } \\
(\mathrm{LSM} \pm \mathrm{SE})\end{array}$ & $\begin{array}{c}\text { Demecolcine treatment alone for } 1 \mathrm{~h} \\
\text { No. of } \\
\text { oocytes }\end{array}$ & $\begin{array}{c}\text { Membrane protrusion rate } \\
(\mathrm{LSM} \pm \mathrm{SE})\end{array}$ \\
\hline 0.4 & 42 & $4.74 \pm 1.71^{\mathrm{a}}$ & 40 & $10.50 \pm 2.09^{\mathrm{a}}$ \\
0.5 & 47 & $4.25 \pm 1.51^{\mathrm{a}}$ & 44 & $9.54 \pm 1.90^{\mathrm{a}}$ \\
0.6 & 46 & $6.52 \pm 1.54^{\mathrm{b}}$ & 46 & $13.62 \pm 1.78^{\mathrm{b}}$ \\
0.7 & 48 & $4.58 \pm 1.74^{\mathrm{a}}$ & 43 & $14.41 \pm 1.94^{\mathrm{b}}$ \\
0.8 & 43 & $23.71 \pm 1.94^{\mathrm{c}}$ & 43 & $24.18 \pm 2.65^{\mathrm{c}}$ \\
\hline
\end{tabular}

Table 2. The effect of co-treatment with demecolcine and sucrose on the membrane protrusion rate of bovine oocytes. Different letters in the same column indicate that the difference between the values was statistically significant $(\mathrm{P}<0.05)$. Bovine oocytes were treated with $0.05 \mathrm{M}$ sucrose in combination with various concentrations of demecolcine for $0.5 \mathrm{~h}$ or $1 \mathrm{~h}$

\begin{tabular}{ccccc}
\hline $\begin{array}{c}\text { Concentration of } \\
\text { demecolcine }(\mu \mathrm{g} / \mathrm{mL})\end{array}$ & $\begin{array}{c}\text { Co-treatment with sucrose for 0.5 h } \\
\text { No. of } \\
\text { oocytes }\end{array}$ & $\begin{array}{c}\text { Membrane protrusion rate } \\
(\mathrm{LSM} \pm \mathrm{SE} \text { ) }\end{array}$ & $\begin{array}{c}\text { Co-treatment with sucrose for } 1 \mathrm{~h} \\
\text { No. of } \\
\text { 0ocytes }\end{array}$ & $\begin{array}{c}\text { Membrane protrusion rate } \\
\text { (LSM } \pm \text { SE) }\end{array}$ \\
\hline 0.4 & 24 & $13.3 \pm 3.48^{\mathrm{a}}$ & 24 & $21.66 \pm 3.48^{\mathrm{a}}$ \\
0.5 & 24 & $45.83 \pm 5.10^{\mathrm{b}}$ & 24 & $50.83 \pm 3.48^{\mathrm{b}}$ \\
0.6 & 25 & $68.00 \pm 4.89^{\mathrm{c}}$ & 25 & $72.80 \pm 3.34^{\mathrm{c}}$ \\
0.7 & 24 & $54.99 \pm 3.48^{\mathrm{b}}$ & 24 & $51.66 \pm 6.97^{\mathrm{b}}$ \\
0.8 & 67 & $67.41 \pm 1.23^{\mathrm{c}}$ & 67 & $68.63 \pm 2.35^{\mathrm{c}}$ \\
\hline
\end{tabular}


Fig. 1. The effects of demecolcine treatment and demecolcine and sucrose co-treatment on the membrane protrusion rates of bovine oocytes. A: Oocytes after $1 \mathrm{~h}$ of demecolcine treatment alone $(0.8 \mu \mathrm{g} /$ $\mathrm{mL})$. Bar $=50 \mu \mathrm{m}$. The yellow arrows indicate the membrane protrusions. B: Hoechst 33342-stained bovine oocytes after $1 \mathrm{~h}$ of demecolcine treatment alone $(0.8 \mu \mathrm{g} / \mathrm{mL})$. Bar $=100 \mu \mathrm{m}$. C: Bovine oocytes after 1 $\mathrm{h}$ of demecolcine and sucrose cotreatment. Bar $=50 \mu \mathrm{m}$. The yellow arrow indicates the membrane protrusion, and the blue arrow indicates the first polar body. D: The enlargement of $\mathrm{C}$. Bar $=25 \mu \mathrm{m}$.

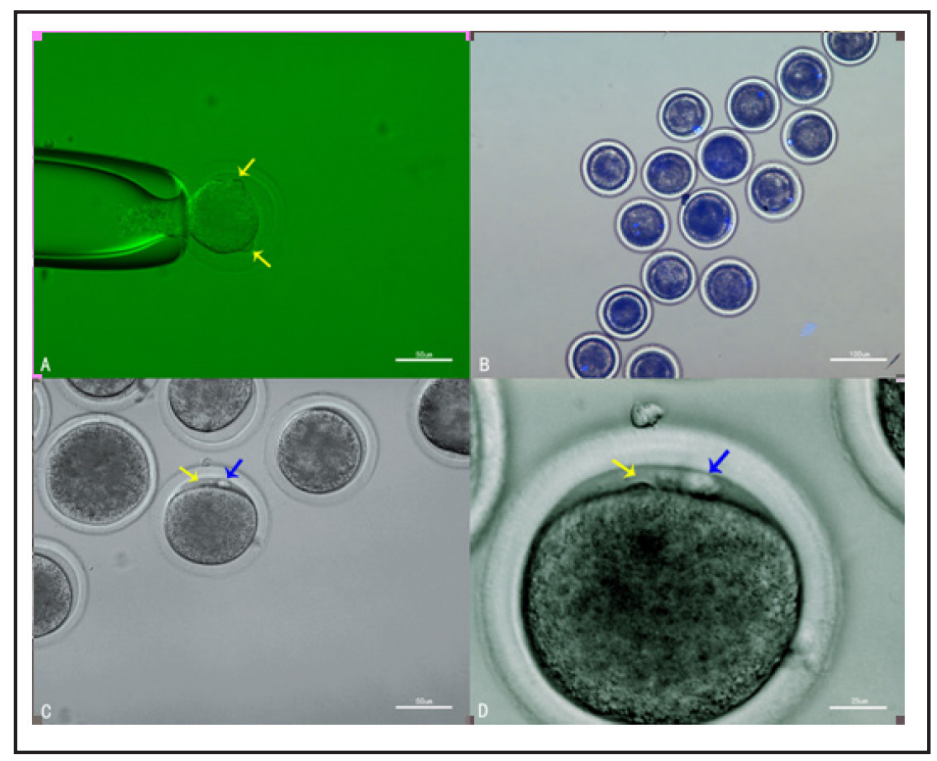

The effect of demecolcine treatment on the membrane protrusion rate of bovine oocyte is summarized in Table 1 . The results demonstrated that when treating for the same period of time, the differences in the membrane protrusion rates were significant after treatment at different demecolcine concentrations $(\mathrm{P}<0.05)$. Regardless of the treatment duration $(0.5 \mathrm{~h}$ or $1 \mathrm{~h})$, treatment with $0.8 \mu \mathrm{g} / \mathrm{mL}$ demecolcine resulted in the highest cell membrane protrusion rate, and multiple membrane protrusions were observed per oocyte (Fig. 1A), which indicated that demecolcine cytotoxicity to the oocytes is enhanced. At a constant demecolcine concentration, the membrane protrusion rate gradually increased with increasing treatment time. The bovine oocytes stained with Hoechst 33342 after $1 \mathrm{~h}$ of demecolcine treatment are shown in Fig. 1B.

The effect of demecolcine and sucrose co-treatment on the membrane protrusion rate of bovine oocytes is shown in Table 2 . The results demonstrated that when the treatment time was held constant, treatment with different concentrations of demecolcine resulted in significantly different membrane protrusion rates $(\mathrm{P}<0.05)$. Regardless of the treatment duration $(0.5 \mathrm{~h}$ or $1 \mathrm{~h})$, treatment with $0.6 \mu \mathrm{g} / \mathrm{mL}$ demecolcine resulted in the highest cell membrane protrusion rates. The oocytes after co-treatment with demecolcine and sucrose for $1 \mathrm{~h}$ are shown in Fig. 1C and 1D.

The fluorescent quantitative PCR results of the maternal gene $c$-mos are shown in Fig. $2 \mathrm{~A}$. The results demonstrated that the $c$-mos gene expression did not exhibit significant differences between the sucrose treatment group and the untreated control group $(\mathrm{P}>0.05)$, whereas significant differences were observed between the demecolcine and sucrose cotreatment group and the other groups $(\mathrm{P}<0.05)$. The MAPK1 western blot results are shown in Fig. 2B, demonstrating that the MAPK1 expression level differed significantly between the demecolcine treatment group and the control group $(\mathrm{P}<0.05)$.

To assess the correlation of position of chromosomes and membrane protrusions, fourty membrane protrusions oocytes treated with demicolicine/sucrose were stained for DNA and microtubules. Co-localisation of chromosomes and membrane protrusions was observed, as shown in Fig. 3. Such a localisation pattern was observed every time. The immunofluorescence staining of the chromosomes, the first polar bodies, and spindles in bovine oocytes clearly demonstrate that the membrane protrusion was caused by chromosomes (Fig. 3). The observation of membrane protrusion demonstrated that the spindles in bovine oocytes were localized at the sites of membrane protrusion. 
Fig. 2. Effects of demecolcine treatment on the expression of the maternal gene c-mos and MAPK1 protein level in the bovine oocytes. A: The comparison of the relative mRNA expression of c-mos among different groups. Oocytes that had matured for $24 \mathrm{~h}$ and had already secreted the first polar body were chosen and divided into 3 groups: a) no treatment, b) treated with $0.05 \mathrm{M}$ sucrose only, and c) treated with both $0.05 \mathrm{M} \mathrm{su}$ crose and $0.6 \mu \mathrm{g} / \mathrm{mL}$ demecolcine. The $c$-mos gene expression did not exhibit significant differences between the sucrose treatment group

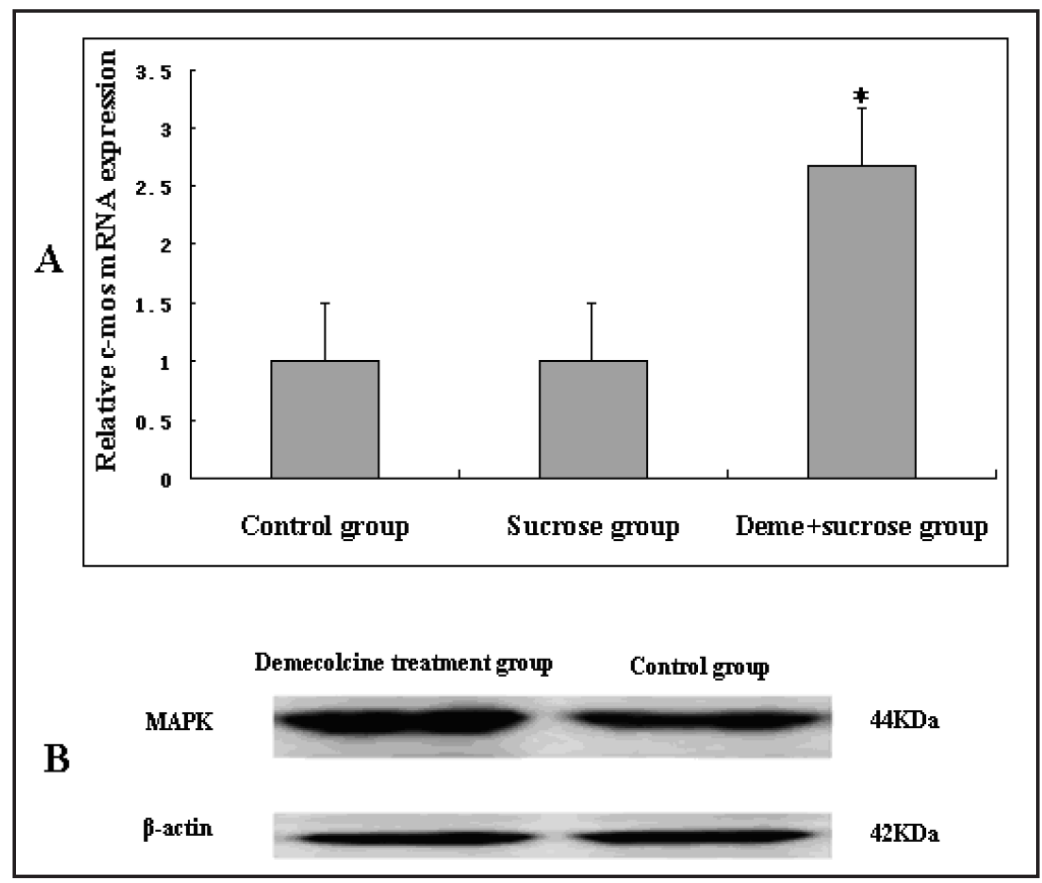
and the untreated control group ( $\mathrm{P}>0.05) .{ }^{*}$ indicates: significant differences were observed between the demecolcine and sucrose co-treatment group and the other groups $(\mathrm{P}<0.05)$. B: The comparison of MAPK1 protein expression between the demecolcine treatment group and the control group.

Fig. 3. Immunofluorescence assay. A: Bovine oocytes after PI staining. Bar $=200 \mu \mathrm{m}$. B: Bovine oocytes after PI staining. Bar $=25 \mu \mathrm{m}$. The yellow arrow indicates the membrane protrusion, also the position of chromosome. The blue arrow indicates the first polar body. C: Bovine oocytes with stained spindle microtubules. Bar $=200 \mu \mathrm{m}$. D: Bovine oocytes with stained spindle microtubules. Bar $=25 \mu \mathrm{m}$. The yellow arrow indicates the membrane protrusion, also the position of chromosome.

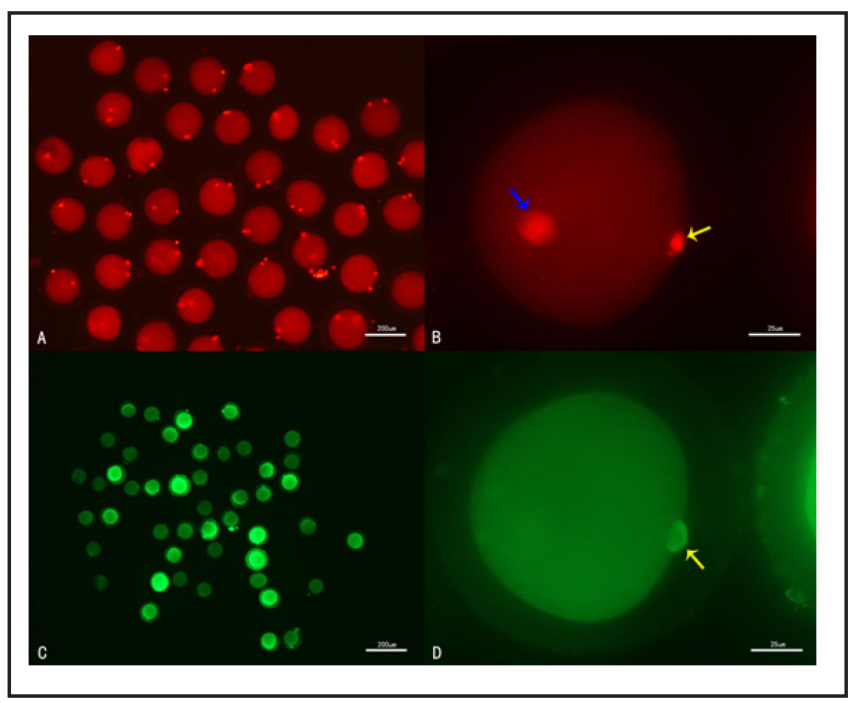

\section{Discussion}

Optimization of the demecolcine treatment

Demecolcine is a chemical reagent that can disrupt spindle stability. Treating bovine oocytes with demecolcine at certain concentrations causes irreversible membrane protrusion. The enucleation can be accurately achieved based on the visible membrane protrusion. Vajta et al. obtained high cloning efficiency with a $48 \%$ blastocyst rate by treating bovine oocytes with demecolcine [13]. Tani et al. reported that treating bovine oocytes with demecolcine for over 30 min caused protrusions in the cell membrane and enhanced MPF activity in the oocytes during the process [14]. During the demecolcine treatment of porcine oocytes, spindles in the oocytes were destroyed, the chromosomes condensed, and cell 
membrane protrusions readily formed [15]. Here, we report that when bovine oocytes were treated for $0.5 \mathrm{~h}$ or $1 \mathrm{~h}$ with demecolcine, the cell membrane protrusion rate increased with the elongation of treatment duration when the demecolcine concentration was constant. The effect of demecolcine treatment on oocytes did not exhibit a linear correlation with the demecolcine concentrations. When the concentration of demecolcine treatment was $0.8 \mu \mathrm{g} /$ $\mathrm{mL}$, the membrane protrusion rate was the highest, which may be associated with the higher osmotic pressure and elevated membrane brittleness caused by demecolcine treatments. The production of multiple membrane protrusions in the oocytes is disadvantageous for accurate enucleation. In this study, we found that the optimal demecolcine concentration was $0.6 \mu \mathrm{g} / \mathrm{mL}$, whereas Saraiva et al. reported in their study that the optimal concentration was $0.4 \mu \mathrm{g} / \mathrm{mL}$ [16]; this disparity may be attributed to different experimental goals. Saraiva et al. attempted to obtain the best subsequent embryo cleavage rate and reconstructed embryo rate; thus, $0.4 \mu \mathrm{g} / \mathrm{mL}$ demecolcine resulted in the least cytotoxicity to bovine oocytes. The focus of our study was to study the maximum membrane protrusion efficiency of demecolcine to investigate the mechanism underlying the formation of membrane protrusions in bovine oocytes caused by demecolcine.

Saito et al. reported that in the demecolcine treatment of mouse oocytes, the general effect of sucrose was limited to cryopreservation; for example, maltose, sorbitol, and sodium chloride all had the same effect [17]. The study also reported that sucrose treatment alone was not able induce any cell membrane protrusions; sucrose was unable to pass through the membrane and could only permeate to the cell's exterior along with water in the oocytes, which is helpful for oocyte shrinkage and provides better conditions for the formation of membrane protrusions.

Our results indicated that sucrose and demecolcine co-treatment of the bovine oocytes helped improve the membrane protrusion rate through a synergistic effect. There are several possible explanations for this synergy. First, sucrose provides a hypertonic environment to induce oocyte shrinkage and increases membrane fragility, which is conducive for demecolcine to penetrate into bovine oocytes to exert its effects. Second, during the demecolcine treatment of bovine oocytes, chromosome condensation occurs, and this process requires achieving a certain energy threshold that can be attained by the energy released during the hydrolysis of sucrose into glucose. Third, during the process of electrofusion, the fusion solution requires sucrose; therefore, the co-treatment with sucrose was beneficial to the subsequent electrofusion [18]. Fourth, high concentrations of demecolcine can cause multiple protrusions in the oocyte; the addition of sucrose helps decrease the concentration of demecolcine. In addition, the demecolcine treatment duration should not be excessive so as to alleviate its cytotoxicity to the oocytes.

The effects of demecolcine treatment on the expression of the maternal gene c-mos and MAPK1 protein levels in bovine oocytes

The ERK1/ERK2 MAP kinases (MAPKs) are transiently activated during mitosis, and MAPK activation has been implicated in the spindle assembly checkpoint and in establishing the timing of an unperturbed mitosis [19-22]. Accordingly, MAPK1 protein levels were increased after demecolcine treatment. The proto-oncoprotein Mos has long been recognized as essential for the activation of MEK1 and MAPK1 during oocyte maturation [23-28]. The c-Mos proto-oncogene product, a serine/threonine kinase, is a strong activator of the MAPK pathway, which is important for oocyte maturation [29, 30]. Moreover, Mos and the MAPK cascade have been established as crucial regulators of second meiotic metaphase arrest in mammalian oocytes. Accordingly, the c-mos mRNA expression level was significantly increased after demecolcine treatment. Demecolcine is a microtubule-disrupting agent that depolymerizes microtubules and limits microtubule formation (inactivating spindle fiber formation). Although the mechanism by which demecolcine elicits its effects is unclear, the present results suggest that demecolcine might contribute to the activation of the Mos/ MAPK pathway and affect spindle structure. These results provide a reference for more efficient generation of enucleated bovine oocytes. 


\section{Abbreviations}

MAPK1 (mitogen-activated protein kinase 1); MPF (maturation-promoting factor); PVA (polyvinyl alcohol); COCs(cumulus-oocyte-complexes); IVM(in vitro maturation); D-PBS (dulbecco's phosphate buffered saline); PI (propidium iodide); LSM (the least squares mean); SE (standard error); ANOVA (one-way analysis of variance); MRT (multiple range test).

\section{Acknowledgments}

This work was supported by the Youth Science Research Fund Program from Jilin Province (20140520176JH), National Natural Science Foundation of China (31030058), the $55^{\text {th }}$ Batch Face Funding Program from China Post-doctoral Science Fund (2014M551197) and the Scientific Frontline and Cross Discipline Program from Jilin University's Basic Scientific Research Affair Expense (450060501490).

\section{References}

1 Wilmut I, Schnieke AE, McWhir J, Kind AJ, Campbell KH: Viable offspring derived from fetal and adult mammalian cells. Nature 1997;385:810-813, erratum in:386:200.

2 Fulka J Jr, Moor RM: Noninvasive chemical enucleation of mouse oocytes. Mol Reprod Dev 1993;34:427430.

- Lee JH, Campbell KH: Effects of enucleation and caffeine on maturation-promoting factor (MPF) and mitogen-activated protein kinase (MAPK) activities in ovine oocytes used as recipient cytoplasts for nuclear transfer. Biol Reprod 2006;74:691-698.

4 Kawakami M, Tani T, Yabuuchi A, Kobayashi T, Murakami H, Fujimura T, Kato Y, Tsunoda Y: Effect of demecolcine and nocodazole on the efficiency of chemically assisted removal of chromosomes and the developmental potential of nuclear transferred porcine oocytes. Cloning Stem Cells 2003;5:379-387.

-5 Russell DF, Ibáñez E, Albertini DF, Overström EW: Activated bovine cytoplasts prepared by demecolcineinduced enucleation support development of nuclear transfer embryos in vitro. Mol Reprod Dev 2005;72:161-170.

-6 Ibáñez E, Albertini DF, Overström EW: Demecolcine-induced oocyte enucleation for somatic cell cloning: coordination between cell-cycle egress, kinetics of cortical cytoskeleton interactions, and second polar body extrusion. Biol Reprod 2003;68:1249-1258.

7 Yin XJ, Tani T, Yonemura I, Kawakami M, Miyamoto K, Hasegawa R, Kato Y, Tsunoda Y: Production of cloned pigs from adult somatic cells by chemically assisted removal of maternal chromosomes. Biol Reprod 2002;67:442-446.

-8 Smith LC: Membrane and intracellular effects of ultraviolet irradiation with Hoechst 33342 on bovine secondary oocytes matured in vitro. J Reprod Fertil 1993;99:39-44.

-9 Wu YG, Zhou P, Lan GC, Gao D, Li Q, Wei DL, Wang HL, Tan JH: MPF governs the assembly and contraction of actomyosin rings by activating RhoA and MAPK during chemical-induced cytokinesis of goat oocytes. PLoS One 2010;5:e12706.

10 Su YQ, Wigglesworth K, Pendola FL, O'Brien MJ, Eppig JJ: Mitogen-activated protein kinase activity in cumulus cells in essential for gonadotropin-induced oocyte meiotic resumption and cumulus expansion in the mouse. Endocrinology 2002;143:2221-2232.

11 Li Z, Sun X, Chen J, Liu X, Wisely SM, Zhou Q Renard JP, Leno GH, Engelhardt JF: Cloned ferrets produced by somatic cell nuclear transfer. Dev Biol 2006;293:439-448.

12 Ono Y, Shimozawa N, Ito M, Kono T: Cloned mice from fetal fibroblast cells arrested at metaphase by a serial nuclear transfer. Biol Reprod 2001;64:44-50.

13 Vajta G, Maddox-Hyttel P, Skou CT, Tecirlioglu RT, Peura TT, Lai L, Murphy CN, Prather RS, Kragh PM, Callesen H: Highly efficient and reliable chemically assisted enucleation method for handmade cloning in cattle. Reprod Fertil Dev 2005;17:791-797. 
14 Tani T, Shimada H, Kato Y, Tsunoda Y: Demecolcine-assisted enucleation for bovine cloning. Cloning Stem Cells 2006;8:61-66.

15 Liu JL, Sung LY, Barber M, Yang X: Hypertonic medium treatment for localization of nuclear material in bovine metaphase II oocytes. Biol Reprod 2002;66:1342-1349.

-16 Saraiva NZ, Perecin F, Méo SC, Ferreira CR, Tetzner TA, Garcia JM: Demecolcine effects on microtubule kinetics and on chemically assisted enucleation of bovine oocytes. Cloning Stem Cells 2009;11:141-152.

17 Saito N, Imai K, Tomizawa M: Effect of sugars-addition on the survival of vitrified bovine blastocysts produced in vitro. Theriogenology 1994;41:1053-1060.

$\checkmark 18$ Miyoshi K, Mori H, Yamamoto H, Kishimoto M, Yoshida M: Effects of demecolcine and sucrose on the incidence of cytoplasmic protrusions containing chromosomes in pig oocytes matured In Vitro. J Reprod Dev 2008;54:117-121.

19 Guadagno TM, Ferrell JE Jr: Requirement for MAPK activation for normal mitotic progression in Xenopus egg extracts. Science 1998;282:1312-1315.

20 Wang XM, Zhai Y, Ferrell JE Jr: A role for mitogen-activated protein kinase in the spindle assembly checkpoint in XTC cells. J Cell Biol 1997;137:433-443.

21 Minshull J, Sun H, Tonks NK, Murray AW: A MAP kinase-dependent spindle assembly checkpoint in Xenopus egg extracts. Cell 1994;79:475-486.

22 Takenaka K, Gotoh Y, Nishida E: MAP kinase is required for the spindle assembly checkpoint but is dispensable for the normal M phase entry and exit in Xenopus egg cell cycle extracts. J Cell Biol 1997;136:1091-1097.

-23 Hashimoto N, Watanabe N, Furuta Y, Tamemoto H, Sagata N, Yokoyama M, Okazaki K, Nagayoshi M, Takeda N, Ikawa Y: Parthenogenetic activation of oocytes in c-mos-deficient mice. Nature 1994;370:68-71.

24 Colledge WH, Carlton MB, Udy GB, Evans MJ: Disruption of c-mos causes parthenogenetic development of unfertilized mouse eggs. Nature 1994;370:65-68.

25 Posada J, Yew N, Ahn NG, Vande Woude GF, Cooper JA : Mos stimulates MAP kinase in Xenopus oocytes and activates a MAP kinase kinase in vitro. Mol Cell Biol 1993;13:2546-2553.

26 Shibuya EK, Ruderman JV: Mos induces the in vitro activation of mitogen-activated protein kinases in lysates of frog oocytes and mammalian somatic cells. Mol Biol Cell 1993;4:781-790.

27 Sagata N, Oskarsson M, Copeland T, Brumbaugh J, Vande Woude GF: Function of c-mos proto-oncogene product in meiotic maturation in Xenopus oocytes. Nature 1988;335:519-525.

28 Nebreda AR, Hunt T: The c-mos proto-oncogene protein kinase turns on and maintains the activity of MAP kinase, but not MPF, in cell-free extracts of Xenopus oocytes and eggs. EMBO J 1993;12:1979-1986.

29 Mansour SJ, Matten WT, Hermann AS, Candia JM, Rong S, Fukasawa K, Vande Woude GF, Ahn NG: Transformation of mammalian cells by constitutively active MAP kinase kinase. Science 1994;265:966970.

-30 Sagata N: What does Mos do in oocytes and somatic cells? Bioessays 1997;19:13-21. 